\title{
Do Students Recognize Ambiguity in Software Design? A Multi-national, Multi-institutional Report
}

\author{
Ken Blaha \\ Computer Science \& Computer \\ Engineering \\ Pacific Lutheran University \\ Tacoma, WA 98447 \\ blahakd@plu.edu
}

\author{
Alvaro Monge \\ Computer Engineering \& \\ Computer Science \\ California State University, Long \\ Beach \\ Long Beach, CA 90840 \\ amonge@csulb.edu
}

\author{
Dean Sanders \\ Computer Science \& Information \\ Systems \\ Northwest Missouri State \\ University \\ Maryville, MO 64468 \\ sanders@mail.nwmissouri.edu
}

\author{
Beth Simon \\ Math \& Computer Science \\ University of San Diego \\ San Diego, CA 92110 \\ bsimon@sandiego.edu
}

\author{
Tammy VanDeGrift \\ Computer Science \& Engineering \\ University of Washington \\ Seattle, WA 98195-2350 \\ tammy@cs.washington.edu
}

\begin{abstract}
Successful software engineering requires experience and acknowledgment of complexity, including that which leads designers to recognize ambiguity within the software design description itself. We report on a study of 21 post-secondary institutions from the USA, UK, Sweden, and New Zealand. First competency and graduating students as well as educators were asked to perform a software design task. We found that as students go from first competency to graduating seniors they tend to recognize ambiguities in under-specified problems. Additionally, participants who recognized ambiguity addressed more requirements of the design.
\end{abstract}

\section{Categories and Subject Descriptors}

K.3.2 [Computer and Information Science Education]: Computer Science Education

\section{General Terms}

Design

\section{Keywords}

requirements, ambiguity, software design

\section{INTRODUCTION}

This work reports on a subset of results from a multinational, multi-institutional study of student-generated software designs [4]. Here we describe results pertaining to participants' recognition of ambiguity in a design brief for which they were asked to produce a design. We say that a participant recognized ambiguity if he asked any questions, other than those of process, or made any assumptions

Copyright is held by the author/owner.

ICSE'05, May 15-21, 2005, St. Louis, Missouri, USA.

ACM 1-58113-963-2/05/0005. during the design. Prior work in comparing the design processes of freshman and senior engineering students found that seniors made more requests for additional information and made more than three times as many assumptions [3]. Recognizing and addressing ambiguity is important because ambiguities in requirements can propagate to errors in the designed solution. It is cheaper to recognize and resolve ambiguities early in the design process [2]. Recognition of ambiguity in the software design specification reflects design maturity, and our work shows that, across a diverse and multi-national sample, recognition of ambiguity is associated with designs that address more requirements. This work should spur discussion on how we educate students with regard to recognizing ambiguity and its importance in the software design process.

\section{THE STUDY}

This study reports on 21 post-secondary institutions in the USA, UK, Sweden, and New Zealand participating in the Scaffolding Research in Computer Science Education NSFsponsored workshop [1]. For additional information about the study please see [4]. First competency students (FC) (defined by [5] as students who could program a simple calculator), graduating seniors (GS), and educators (E) were asked to perform two tasks: a software decomposition task (on paper) and a design criteria prioritization task. The latter is not discussed in this paper. The dataset includes 303 participants (131 FC, 145 GS, 27 E). Each participant was given a design brief specifying a "super alarm clock". The design brief stated:

In doing this you should (1) produce an initial solution that someone (not necessarily you) could work from (2) divide your solution into not less than two and not more than ten parts, giving each a name and adding a short description of what it is and what it does - in short, why it is a part. If important to your design, you may 
indicate an order to the parts, or add some additional detail as to how the parts fit together. [4]

Participants were explicitly invited to ask questions and to take as long as they wished.

\section{RECOGNITION OF AMBIGUITY}

We define two subpopulations within our study. The recognizers are participants who either asked a non-procedural question or made an explicit assumption in the design process. The information gatherers, a subset of the recognizers, ask questions and may or may not make observable assumptions. We recognize a source of bias in that our definitions of subpopulations are based on observable behavior (asking questions and making explicit assumptions). Participants making assumptions without externalizing them are not defined as recognizers in this work and, consequently, the number of participants making assumptions may be larger than reported.

\section{PERFORMANCE ANALYSIS}

Table 1 shows a greater percentage of graduating students recognized ambiguity than first competency students. The same can be said of information gatherers. Educators overwhelmingly recognize ambiguity. Note that $36 \%(78 / 216)$ of recognizers simply made assumptions without gathering information. Of FC recognizers, $48 \%$ simply made assumptions. This is consistent with the practices of beginning engineering students [3]. Table 2 shows the percentages of recognizers and information gatherers by country.

Table 1: Recognizers and Information Gatherers

\begin{tabular}{|l|l|l|l|l|}
\hline & $\begin{array}{l}\text { FC } \\
(\mathrm{N}=131)\end{array}$ & $\begin{array}{l}\text { GS } \\
(\mathrm{N}=145)\end{array}$ & $\begin{array}{l}\mathrm{E} \\
(\mathrm{N}=27)\end{array}$ & $\begin{array}{l}\text { All } \\
(\mathrm{N}=303)\end{array}$ \\
\hline Percent Rec- & $63 \%$ & $76 \%$ & $89 \%$ & $71 \%$ \\
ognizers & $(82)$ & $(110)$ & $(24)$ & $(216)$ \\
\hline Percent & $33 \%$ & $50 \%$ & $81 \%$ & $46 \%$ \\
Information & $(43)$ & $(73)$ & $(22)$ & $(138)$ \\
Gatherers & & & & \\
\hline
\end{tabular}

Table 2: Recognizers and Information Gatherers By Country

\begin{tabular}{|l|l|l|l|l|}
\hline & Sweden & UK & NZ & USA \\
\hline $\begin{array}{l}\text { \% FC Recog- } \\
\text { nizers }\end{array}$ & $62 \%$ & $100 \%$ & $40 \%$ & $61 \%$ \\
$(8 / 13)$ & $(10 / 10)$ & $(4 / 10)$ & $(60 / 98)$ \\
\hline $\begin{array}{l}\text { \% GS Recog- } \\
\text { nizers }\end{array}$ & $79 \%$ & $100 \%$ & $50 \%$ & $76 \%$ \\
\hline $\begin{array}{l}\text { \% FC Info } \\
\text { Gatherers }\end{array}$ & $54 \%$ & $50 \%$ & $30 \%$ & $29 \%$ \\
\hline $\begin{array}{l}\text { \% GS Info } \\
\text { Gatherers }\end{array}$ & $57 \%$ & $10 \%$ & $50 \%$ & $53 \%$ \\
\hline
\end{tabular}

Recognizers were also more successful at addressing the requirements outlined in the design task. Each participant's design was categorized by how well it addressed requirements: Yes (all 9 requirements addressed), Partially (5-8 addressed), Hardly (1-4 addressed), No (0 addressed), NA (no data about requirements). Table 3 shows the performance of each group in satisfying the requirements. Almost half of the recognizers addressed all the requirements, while
Table 3: Addressing Requirements By Population

\begin{tabular}{|l|l|l|l|l|l|}
\hline & Yes & Partially & Hardly & No & NA \\
\hline Recognizers & $45 \%$ & $47 \%$ & $6 \%$ & $1 \%$ & $1 \%$ \\
N=216 & $(97)$ & $(101)$ & $(14)$ & $(2)$ & $(2)$ \\
\hline Non- & $26 \%$ & $58 \%$ & $14 \%$ & $2 \%$ & $0 \%$ \\
Recognizers & $(23)$ & $(50)$ & $(12)$ & $(2)$ & $(0)$ \\
N=87 & & & & & \\
\hline
\end{tabular}

only $26 \%$ of non-recognizers did. The results for information gatherers are similar.

Additionally, of those who addressed all requirements ( N $=120), 81 \%$ were recognizers. Of those who partially addressed the requirements $(\mathrm{N}=151), 67 \%$ were recognizers.

\section{CONCLUSIONS}

This work raises some important questions for educators. What can we do to help students recognize ambiguities in specifications? How should students be taught to resolve ambiguity in specifications? At what point in an undergraduate curriculum should we intentionally introduce ambiguity into problem statements?

This work describes a multi-national, multi-institutional study of student designs which reveals that recognition of ambiguity is more common among graduating seniors than first competency students and that the majority of participants $(81 \%)$ who addressed all requirements in the design also recognized ambiguity.

\section{REFERENCES}

[1] http://depts.washington.edu/srcse/.

[2] B. W. Boehm. Software Engineering Economics. Prentice Hall, Upper Saddle River, New Jersey, 1981.

[3] K. M. Bursic and C. J. Atman. Information Gathering: A Critical Step for Quality in the Design Process. Quality Management Journal, 4(4):60-75, 1997.

[4] S. Fincher, M. Petre, J. Tenenberg, K. Blaha, D. Bouvier, et al. Cause for alarm?: A multi-national, multi-institutional study of student-generated software designs. Technical Report 16-04, Computing Laboratory, University of Kent, Canterbury, September 2004. http://www.cs.kent.ac.uk/pubs/2004/1953.

[5] W. M. McCracken et al. A multi-national, multi-institutional study of assessment of programming skills of first-year CS students. SIGCSE Bulletin, 33(4):125-180, 2001.

Acknowledgments: We thank the participants and leaders of the Scaffolding Workshop for CS Education Research for their help in data collection and analysis. We especially thank all the students and educators who participated in the study. This material is based upon work supported by the National Science Foundation under Grant No. DUE0243242. Any opinions, findings, and conclusions or recommendations expressed in this material are those of the authors and do not necessarily reflect the views of the $\mathrm{Na}$ tional Science Foundation. 